This document was prepared in conjunction with work accomplished under Contract No. DE-AC09-96SR18500 with the U. S. Department of Energy.

\title{
DISCLAIMER
}

This report was prepared as an account of work sponsored by an agency of the United States Government. Neither the United States Government nor any agency thereof, nor any of their employees, makes any warranty, express or implied, or assumes any legal liability or responsibility for the accuracy, completeness, or usefulness of any information, apparatus, product or process disclosed, or represents that its use would not infringe privately owned rights. Reference herein to any specific commercial product, process or service by trade name, trademark, manufacturer, or otherwise does not necessarily constitute or imply its endorsement, recommendation, or favoring by the United States Government or any agency thereof. The views and opinions of authors expressed herein do not necessarily state or reflect those of the United States Government or any agency thereof.

This report has been reproduced directly from the best available copy.

Available for sale to the public, in paper, from: U.S. Department of Commerce, National Technical Information Service, 5285 Port Royal Road, Springfield, VA 22161, phone: (800) 553-6847, fax: (703) 605-6900

email: orders@ntis.fedworld.gov

online ordering: http://www.ntis.gov/help/index.asp

Available electronically at http://www.osti.gov/bridge

Available for a processing fee to U.S. Department of Energy and its contractors, in paper, from: U.S. Department of Energy, Office of Scientific and Technical Information, P.O. Box 62, Oak Ridge, TN 37831-0062,

phone: (865)576-8401,

fax: (865)576-5728

email: $\underline{\text { reports@ adonis.osti.gov }}$ 
WSRC-TR-2002-00341

Revision 0

Keywords: Filtration

Sludge, Salt Processing

Retention: Permanent

\section{Recommendation for Using Smaller (0.1 $\mu$ ) Pore-Size Media for Filtration in Salt Waste Processing Project}

Michael R. Poirier and Samuel D. Fink

Savannah River Technology Center Westinghouse Savannah River Company

August 5, 2002 
WSRC-TR-2002-00341

Revision 0

THIS PAGE INTENTIONALLY LEFT BLANK 


\section{SUMMARY}

Based on experimental studies with simulated and actual wastes, we recommend adopting the use of 0.1-micron pore-size, sintered stainless-steel filter elements within the design of the Salt Waste Processing Facility. Furthermore, adopting the smaller pore size elements for the Actinide Removal Process would result in a significant risk to the start-up schedule due to delays for buying, installing, and testing new equipment. The existing 0.5-micron pore-size filters will provide nearly equivalent service with no additional capital investment. Unless the planned filter test at Building 512-S fails to meet specifications, the project should proceed with the existing equipment, including spares. When the existing equipment reaches the end of the service life, management can consider replacement with the smaller pore-size elements. The laboratory studies indicate that use of the smaller pore size equipment will result in greater protection against particulate fines passing to downstream facilities while giving equivalent or superior processing rates than provided by the 0.5 -micron elements.

Given the limited duration of the laboratory testing, we further recommend conducting longer duration studies with simulated waste at larger scale. Such studies will examine the impact of the smaller pore size on frequency of the cleaning operation and on the processing rate for the equipment. Procurement of filter elements for testing at the University of South Carolina began in support of this program recommendation.

\section{TECHNICAL BASES}

The prior efforts on the conceptual design for the Salt Waste Processing Facility assumed use of a 0.5 micron pore-size, cross-flow filter manufactured by Mott Corporation. ${ }^{1}$ Use of this configuration derived from prior experience at Savannah River Site using the equipment for filtration of slurries containing sludge, monosodium titanate, and tetraphenylborate solids. The Salt Processing Program examined the use of this filter media in several demonstrations with simulated and actual wastes in equipment at laboratory-scale through pilot scale., , $^{2,4,5,6,7}$ However, personnel observed passage of solids through one such filter at the University of South Carolina, raising doubts as to the adequacy of the selection. Similarly, the waste treatment program at Hanford adopted the use of 0.1 micron elements for the analogous step in the process based in large part on proprietary studies conducted by British Nuclear Fuels Limited in support of the Sellafield operations.

In light of these observations, the Salt Processing Program elected to examine the use of 0.1-micron elements to judge their relative performance. Personnel conducted a series of laboratory tests using both simulated ${ }^{8}$ and actual wastes. ${ }^{9}$

Figure 1 shows the turbidity in filtrate samples taken from experiments using simulated waste. ${ }^{8}$ These studies used slurries of monosodium titanate and sludge with a single cross-flow element. The tests occurred at elevated operating pressures and velocities that conservatively bound those anticipated in either the Salt Waste Processing Facility or the Actinide Removal Process. The amount of solids passing the filter proved smallest for the 0.1-micron elements. 
Similarly, Figure 2 shows the relative filter performance as measured by flux for different filter elements in the same experiments. ${ }^{8}$ The 0.1 -micron element provided greater or equivalent flux - i.e., "throughput" - when compared to the baseline, 0.5-micron equipment. The exception occurred for the "cleaned" 0.5-micron element. However, Figure 1 showed that solids passage proved greatest for the "cleaned" 0.5 -micron element and approached values that could exceed the allowable radionuclide transfer to downstream facilities.

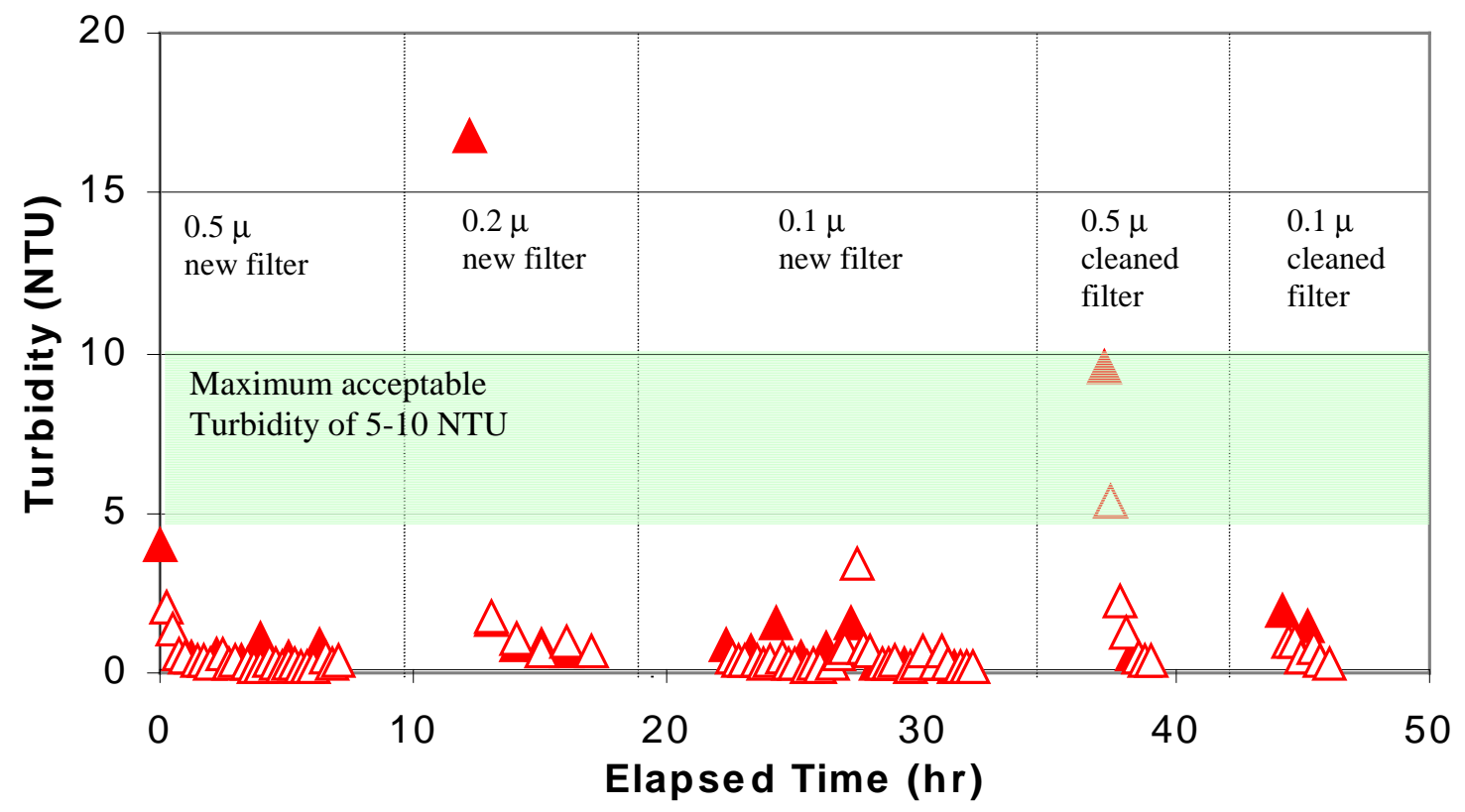

Figure 1. Turbidity of filtrate from experiments using simulated waste slurries and filter elements with different pore size. Maximum allowable turbidity estimated at 5-10 NTU. ${ }^{10}$

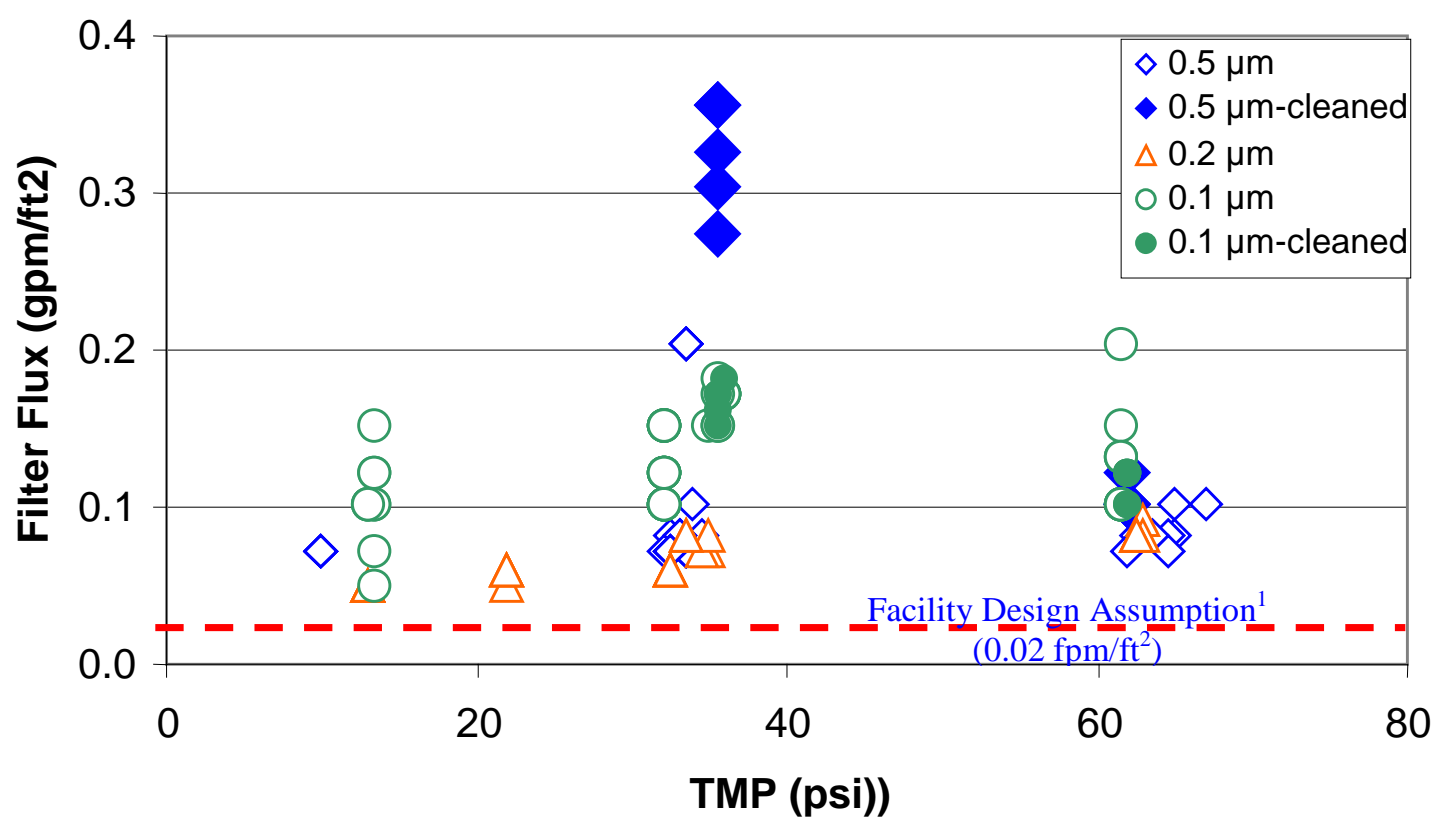


Figure 2. Relative filter performance from experiments using simulated waste slurries and filter elements with different pore size.

Figure 3 shows similar filter performance from experiments using actual waste. ${ }^{9}$ Again, these studies used operating pressures and velocities expected to bound those anticipated in either the Salt Waste Processing Facility or the Actinide Removal Process. The sample of sludge slurry came from Tank $40 \mathrm{H}$. Personnel treated the sludge slurry with either monosodium titanate or sodium permanganate to remove soluble strontium and alpha-emitting actinides. Testing used a single filter element. For either process option, the 0.1 -micron element provided equal or superior performance.

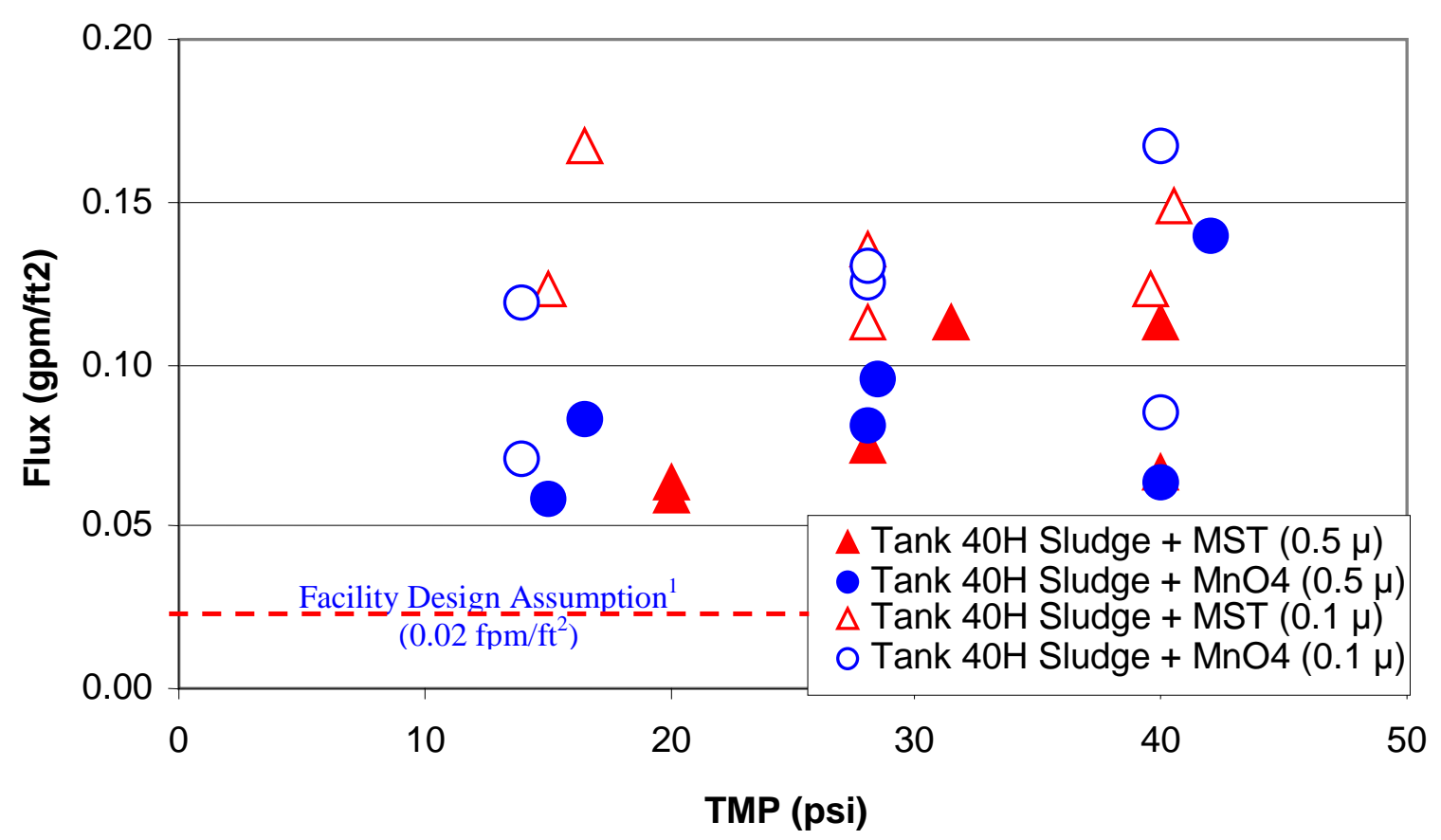

Figure 3. Relative filter performance from experiments using actual waste slurries and filter elements with different pore size.

The scope of testing for either simulated or actual waste included relatively short duration testing. No single experiment lasted longer than 8 hours in these studies. Hence, the work did not define the long-term behavior of the smaller filter element. In addition, the studies do not provide any discrimination of the relative frequency for required chemical cleaning of the different sized filter elements. The program should study the performance at larger scale and for longer duration to assess these issues. 


\section{ASSESSMENT USING THE PROJECT CRITERIA}

The original HLW systems evaluation to select the current configuration assessed each unit operation and the entire process against the criteria shown in Table I. $^{11}$ Adoption of new equipment or unit operations should first consider the impact of the decision along these lines of inquiry. The authors made a preliminary assessment of the impact on the scoring considering deployment either in the Salt Waste Processing Facility or within the Actinide Removal Process. Table I summarizes our assessment.

Use of the 0.1 micron filter elements appears to offer a slight increase in filtration rate and hence a minor savings in life cycle costs. However, full assessment of the impact on process cycle time requires an understanding of the influence on required frequency of chemical cleaning. The limits of the current data do not allow a reliable numerical interpretation of the benefit.

Table I. Selection Criteria for Process Options.

\begin{tabular}{|l|c|c|}
\hline \multicolumn{1}{|c|}{ Criterion } & $\begin{array}{c}\text { Impact of Recommended } \\
\text { Equipment Change on Scoring } \\
\text { for Project }\end{array}$ \\
\cline { 2 - 3 } & $\underline{\text { SWPF }}$ & $\underline{\text { ARP }}$ \\
\hline Schedule Risk & No change & Increase \\
\hline Project Reduction Potential & No change & No change \\
\hline Life Cycle Costs Through D\&D & Decrease & Decrease \\
\hline Technical Maturity & Decrease & Decrease \\
\hline Implementation Confidence & No change & No change \\
\hline Minimizing Environmental Impacts & Improve & Improve \\
\hline $\begin{array}{l}\text { Impacts of Interface to DWPF and Downstream } \\
\text { Facilities (e.g., Solvent Extraction) }\end{array}$ & Improve & \begin{tabular}{c} 
Improve \\
\hline Process Simplicity to Interfacing Systems
\end{tabular} \\
\hline Levels of Safety Control Mitigation & No change & No change \\
\hline Maximize Process Flexibility in Throughput & No change & No change \\
\hline Maximize Process Simplicity (Operability) & No change & No change \\
\hline \multicolumn{1}{|c|}{ Overall } & No change \\
\hline & Improvement & Improvement \\
\hline
\end{tabular}

Less data exists on the use of the smaller pore size elements and hence this option suffers a slightly reduced score versus the criterion for technical maturity. The 0.1 micron elements do ensure less particulate fines would pass to downstream facilities such as the contactors in the solvent extraction process. Similarly, fewer alpha-containing solids would eventually route to the Saltstone Production Facility. Hence, the use of the equipment results in a more favorable rating relative to minimizing impacts to downstream facilities. For the remaining criteria, the selected filter element does not provide any discrimination in the ratings.

On first evaluation for the Salt Waste Processing Facility, the use of 0.1-micron pore-size elements results in a more favorable process rating. In contrast, adopting the smaller pore size elements for the Actinide Removal Process would result in a significant risk to the start-up 
schedule due to delays for buying, installing, and testing new equipment. The existing 0.5-micron pore-size filters will provide nearly equivalent service with no additional capital investment. Unless the planned filter test at Building 512-S fails to meet specifications, the project should proceed with the existing equipment, including spares. When the existing equipment reaches the end of the service life, management can consider replacement with the smaller pore-size elements.

\section{REFERENCES}

${ }^{1}$ R. A. Dimenna, H. H. Elder, J. R. Fowler, R. C. Fowler, M. V. Gregory, T. Hang, R. A. Jacobs, P. K. Paul, J. A. Pike, P. L. Rutland, F. G. Smith III, S. G. Subosits, G. A. Taylor, S. G. Campbell, and F. A. Washburn, "Bases, Assumptions, and Results of the Flowsheet Calculations for the Decision Phase Salt Disposition Alternatives," WSRC-RP-99-00006, Rev. 3, May 2001.

${ }^{2}$ H. H. Saito, M. R. Poirier, and J. L. Siler, "Effect of Sludge Solids to Monosodium Titanate (MST) Ratio on MST-Treated Sludge Slurry Cross-Flow Filtration Rates," WSRC-TR-99-00342, September 15, 1999.

${ }^{3}$ H. H. Saito, M. R. Poirier, S. W. Rosencrance, and J. L. Siler, "Improving Filtration Rates of Mono-Sodium Titanate (MST)-Treated Sludge Slurry with Chemical Additives," WSRC-TR-99-00343, September 15, 1999.

${ }^{4}$ M. R. Poirier, F. F. Fondeur, T. L. Fellinger, and S. D. Fink, "Cross-flow Filtration Demonstration for Slurries Containing High Level Waste Sludge and Monosodium Titanate," WSRC-TR-2001-00212, April 11, 2001.

${ }^{5}$ R. Haggard, C. Stork, T. Deal, and V. Van Brunt, "Final Report on the Crossflow Filter Testing for the Salt Disposition Alternative," USC-FRED-PSP-RPT-09-0-010, Rev. 0, December 4, 1998.

${ }^{6}$ R. Haggard, V. Van Brunt, C. Stork, and T. Deal, "Final Report on the Crossflow Filter Optimization with 5.6 M Sodium Salt Solution," USC-FRED-PSP-RPT-09-0-015, December 20, 2000.

${ }^{7}$ V. Van Brunt, R. Haggard, T. Deal, C. Stork, M. Poirier, and S. D. Fink, "Cross-Flow Filtration of Simulated High-Level Waste Sludge (Tank 8F),” WSRC-TR-2001-00195, April 20, 2001.

${ }^{8}$ M. R. Poirier, T. M. Jones, S. D. Fink, V. Van Brunt, and R. Haggard "Evaluation of Mott Filter Performance: Solids Removal Efficiency,” WSRC-TR-2002-00256, May 30, 2002.

${ }^{9}$ M. R. Poirier, J. L. Siler, and S. D. Fink, "Filtration of Actual Savannah River Waste Treated with Permanganate or Monosodium Titanate," WSRC-TR-2002-00134, March 14, 2002.

10 M. R. Poirier, M. A. Norato, and S. D. Fink, "Evaluating Centrifuges for Solid-Liquid Separation in the SRS Salt Processing Program," WSRC-TR-2001-00555, November 16, 2001.

${ }^{11}$ H. D. Harmon, J. A. Murphy, and R. Smalley, "Savannah River Site Salt Processing Project Down Selection Decision Analysis Report,” TFA-0106, Rev. 0, June 2001. 